\title{
Original Research Article \\ Histopathological study of meningioma in a tertiary care centre: a two years experience
}

\author{
Khade S. ${ }^{1}$, Waghmare R. ${ }^{2}$, Shenoy A. ${ }^{3}$ \\ ${ }^{1}$ Dr. Shalaka Khade, Ex-Resident, Department of Pathology, Topiwala National Medical College, Mumbai, ${ }^{2}$ Dr. Ramesh \\ Waghmare, Assistant Professor, Department of Pathology, Topiwala National Medical College, Mumbai, ${ }^{3}$ Dr. Asha \\ Shenoy, Professor, Department of Pathology, Seth G. S. Medical College, Mumbai, India.
}

Corresponding Author: Dr. Ramesh Waghmare, Assistant Professor, Department of Pathology, Topiwala National Medical College, Mumbai, India. E-mail: rameshpathmumbai@gmail.com, shalakakhade18@gmail.com, shenoyasha@yahoo.co.in

\begin{abstract}
Background: Meningioma is a neoplasm arising from the arachnoidal cap cells in the meningeal coverings of the spinal cord and brain. These are the most common benign intracranial tumours and account for about $13-26 \%$ of all primary brain neoplasms. These are generally benign neoplasms, but about $10 \%$ are atypical or malignant. Objective: To study the variants and histopathological spectrum of meningioma. Material \& Methods: This study includes 29 cases of meningioma diagnosed over a period of two years. Result: Most common variant was noted to be meningothelial meningioma followed by transitional meningioma. Out of the 29 cases, grade I were $96.55 \%$ whereas grade II were $3.44 \%$. Conclusion: From our study, we conclude that meningothelial meningioma is the most common variant. Benign meningiomas are the most common type.
\end{abstract}

Keywords: Meningioma, WHO grading, WHO classification

\section{Introduction}

The term 'Meningioma' was coined by Harvey Cushing in the year 1922. Meningiomas are the most common primary intracranial neoplasms arising from the leptomeninges. These account for about $13-26 \%$ of all primary brain neoplasms [1]. These are predominantly located in the cerebral hemisphere, but occurrence at other sites has also been noted. Most of the meningiomas are benign and are categorized as WHO grade I. Atypical meningiomas account for about 4.7$7.2 \%$ of meningiomas; whereas anaplastic meningiomas comprise between $1.0-2.8 \%$ of meningiomas [2,3].

The origin of meningioma is thought to be from the arachnoidal cap cells in the meningeal coverings of the brain and spinal cord[4].Meningiomas have dural attachment and are well-demarcated rounded or lobular masses. Parafalcine meningiomas are usually irregular, dumbbell shaped[5].En plaque meningioma is a specific clinicopathological entity, which is locally invasive, but usually is histologically benign. These are usually located in sphenoidal region, calvarium and spinal region and grow in a sheetlike pattern [6]. A small

Manuscript received: $2^{\text {nd }}$ January 2019

Reviewed: $10^{\text {th }}$ January 2019

Author Corrected: $16^{\text {th }}$ January 2019

Accepted for Publication: $20^{\text {th }}$ January 2019 number of meningiomas tend to lack circumscription and involve the adjacent brain parenchyma indicating aggressive nature of tumour. Cut surface of meningioma may vary depending upon the histological features. These are usually light tan to brown in colour. Angiomatous meningioma has a haemorrhagic appearance due to prominence of vascular channels. Microcystic meningiomas usually have a soft and spongy texture due to presence of numerous small cystic spaces [7].

Histological grading of meningioma is known to have prognostic and therapeutic implications. Histologically, meningiomas show considerable heterogeneity. Several histological features are associated with either benign or aggressive behaviour. Various histological features that are included for diagnosis and classifying meningioma include tissue pattern, cellular morphology, mitotic activity, necrosis, presence of psammoma bodies, and infiltration of underlying brain parenchyma. Features taken into consideration for higher grading of meningioma include mitotic rate, high cellularity, small cell change (high nuclear to cytoplasm ratio), macronucleoli, pattern less growth, foci of necrosis and brain invasion [4]. 
Mitotic count is assessed in the areas of highest mitotic count, calculating number of mitotic figures in ten consecutive non-overlapping high power fields. Sheeting is defined as lack of typical meningioma growth patterns, and is noted when this covers more than half of the field at $10 \mathrm{X}$ magnification. Macronucleoli are said to be present when they are recognized at $10 \mathrm{X}$ power.

Small cell formation is characterized by high nuclear to cytoplasm ratio. Many other studies correlated several histological features like fibrosis, hyper vascularization, nuclear pleomorphism, apoptosis, vesicular nuclei, presence of lymphocytes, lipidization, etc[4].

The WHO classification of tumours of the central nervous system [2] determines 15 separate histopathological variants of meningiomas that correspond with 3 grades of malignancy: benign meningiomas (grade I), atypical meningiomas (grade II) and malignant meningiomas (grade III) $[2,8]$.

An update of the 2007 WHO classification was introduced in 2016. In which brain invasion was introduced as a criterion for the diagnosis of atypical meningiomas, WHO grade II, which can alone suffice for diagnosing an atypical meningioma [9]. The aim of this study is to classify meningioma and its variants based on histology.

\section{Material and Methods}

Study design: A hospital based retrospective study was undertaken which included 29 diagnosed cases of meningioma. This study has been carried out in a tertiary care hospital in Mumbai over a period of two years.

Sample collection \& method: The hematoxylin and eosin stained sections were studied. Special stains were taken into consideration wherever needed. Microscopic features were studied and criteria outlined in the latest WHO Classification of Tumours of CNS 2016 were used for diagnosis and categorization of meningioma.

Inclusion criteria: Patients diagnosed as Meningioma during the study period in the Department of Pathology were included.

Exclusion criteria: Patients with inadequate biopsy specimen and the specimens with diagnosis other than Meningioma.

Statistical analysis: Data was analysed in the form of tables and percentage.

\section{Results}

During the study period, 29 cases of meningioma were studied histologically. The most common variant was found to be meningothelial meningioma (34.48\%) followed by transitional meningioma $(27.58 \%)$. The other variants found were psammomatous meningioma (17.24\%), angiomatous meningioma (10.34\%), fibrous meningioma (3.44\%), secretory meningioma (3.44\%) and atypical meningioma (3.44\%) (Table 1) (Figure 1, 2 ). Most of the variants belonged to WHO grade I $(96.55 \%)$. There was only one case of grade II meningioma during the study period (3.44\%) (Table 2). We noted meningothelial, transitional and psammomatous meningioma as the most common subtypes.

Among the 29 cases, 20 were female and 9 were male. Male: female ratio was 1:2.2. Thus, female predominance was noted. Most common age group affected was 31-60 years, consisting of 18 cases out of 29 (Table 3).

\section{Discussion}

Meningiomas have heterogenous histological picture and are divided into three grades according to WHO classification of tumours of the central nervous system. This grading system is of prognostic importance. Most of the meningiomas are benign, but few have atypical and malignant features. Higher grade of meningioma are associated with increased chances of recurrence and biologically aggressive behaviour. Histology is an important tool for categorizing meningioma into various subtypes and WHO grading.

In the present study, 29 cases of meningioma were studied with the aim to study the histopathological features of meningioma and to classify meningioma based on histology according to the WHO Classification 2016.

Out of 29 cases in our study, 28 cases belonged to WHO grade I $(96.55 \%)$ whereas there was only one case of WHO grade II (3.44\%). We did not find any case of WHO grade III. In a study by Shah et al, grade I meningioma were $92 \%$, grade II were $8 \%$ and grade III were $5.9 \%$ [10]. Gadgil et al 94, in his study on meningioma noted $85.6 \%$ grade I, $11.5 \%$ grade II and $2.9 \%$ grade III [11].

The results in both these studies were similar to our study. Many other studies in literature found grade I to be the most common type of meningioma [12]. Meningothelial, Transitional and fibrous meningioma constitute the most common variants in many studies (Table 4) $[10,11,13]$. In contrast, our study showed 
fibrous meningioma as one of the uncommon variants. Another variation found in our study was the comparably higher percentage of angiomatous meningioma. This variation could be as a result of the smaller sample size. Our study showed 10 cases of meningothelial meningioma $(34.48 \%)$ followed by 8 cases of transitional meningioma $(27.58 \%)$. The study conducted by Reddy et al [12] demonstrated meningothelial meningioma to be $42.1 \%$, while transitional meningioma were $10.5 \%$. In meningothelial meningioma, the meningothelial cells were arranged in syncytium and lobules.

These lobules were separated by thin collagenous septae. Most of these cases showed oval nuclei with delicate nuclear chromatin. Some cases showed rounded eosinophilic cytoplasmic invaginations, and some cases demonstrated central nuclear clearing. Transitional meningioma constituted tumour cells arranged in syncytial pattern at places as well as interlacing fascicles and bundles. This formed both meningothelial and fibrous pattern.

We found 5 cases (17.24\%) of psammomatous meningioma in our study which were comparable to study by Shah et al [10] showing $19 \%$ cases of psammomatous meningioma. Psammomatous meningioma is characterized by presence numerous psammoma bodies which outnumbered the meningothelial component. In some cases, these formed irregular calcified bodies. Some studies have found psammoma bodies to have a protective role [13].

There were 3 cases $(10.34 \%)$ of angiomatous meningioma in our study. Study done by Desai et al [14] showed similar results by noting $9.09 \%$ cases of angiomatous meningioma. This type is characterized by abundance of blood vessels. The blood vessels were variable in size with some vessels showing increased wall thickness and others were thin walled. At places, the meningothelial component was suppressed due to the abundance of blood vessels. Angiomatous meningioma is a rare variant of meningioma. MRI shows some typical features like perilesional edema due to increased vascularity[15].

Other subtypes in our study include one case each of fibrous, secretory and atypical meningioma (3.44\%). Histologically, fibrous meningioma consisted of spindle cells arranged in storiform pattern and interlacing bundles.

Collagen rich matrix was also seen. Secretory meningioma demonstrated intracellular lumina with presence of eosinophilic secretions within showing

\section{Original Research Article}

positivity with PAS staining. These cases accounted for $1.35 \%$ in the study done by Wang et al [16] and $2.96 \%$ in the study by Regelsberger et al[17], which were in concordance with our study. We did not find other variants of grade I meningioma i.e. microcystic, lymphoplasmacyte-rich and meta plastic during our study period. Atypical meningiomas include types having certain histological parameters that are associated with increased risk of recurrence and more aggressive behaviour than benign forms.

These include meningioma with (a) mitotic index more than 4 per 10 high power fields OR (b) 3 of the 5 features which include- patternless growth, hyper cellularity, high nucleus: cytoplasm ratio, macronucleoli and geographic areas of necrosis OR (c) Brain invasion. The case of grade II atypical meningioma in our study demonstrated presence of brain invasion. Brain invasion is defined as irregular tongue-like protrusions of tumour cells infiltrating into the underlying brain parenchyma without an intervening layer of leptomeninges [18]. Other specific subtypes included in grade II are chordoid and clear cell meningioma.

The most aggressive form fall into grade III which include anaplastic, rhabdoid and papillary meningioma. These account for $1.0-2.8 \%$ of meningiomas. The criteria for anaplastic meningioma includes: Mitotic index $\geq 20$ mitosis/10 HPF or features of anaplasia (sarcoma, carcinoma or melanoma like histology)[2]. During our study period, we did not find any grade III case.

Most common age group affected in our study was 3160 years with a female predominance. Immunohistochemistry (IHC) mainly has a role in differential diagnosis, for example, when distinguishing meningioma from hemangiopericytoma or other mesenchymal tumours. Majority of the meningiomas stains positive for epithelial membrane antigen (EMA). Vimentin positivity is also seen in all meningiomas. The intermediate filaments in meningiomas that are composed of vimentin give a consistent positive immunostaining with antibodies to this protein.

Variable positivity is seen for S-100. Secretory meningiomas demonstrate a characteristic positivity for cytokeratin and carcinoembryonic antigen. Some of these tumours also show positive staining for other IHC markers including claudin-1, CD99, bcl-2 and Factor XIIIa have also been noted in some of these tumours [5]. An important role for immunohistochemistry in meningioma diagnostics lies in the assessment of the proliferative index, which in clinical pathology is usually measured with the antibody MIB-1. MIB-1 is 
the clone that targets the proliferation marker Ki-67 in paraffin embedded tissue. Raised MIB-1 labelling indices are associated with increased risk of recurrence. Demonstration of progesterone receptors also have a role in meningiomas [19]. Many studies have demonstrated higher PR expression in benign compared to aggressive forms. It was also reported that positive

\section{Original Research Article}

progesterone receptors are associated with less recurrence rate. These have inverse relationship with Ki-67 proliferative index, and thus associated with better prognosis [21]. Asimmunohisto chemistry was not available at our institute; patients were referred for IHC to the oncology institution.

\section{Conclusion}

Meningiomas are predominantly benign neoplasms of the central nervous system. Histopathological examination is an imperative tool for confirmatory diagnosis due to the diverse histological variants. Also, the prognosis of the disease depends on histopathological grading of the lesion.

The accuracy of histopathological diagnosis and grading of meningioma requires a continuous revision of histopathology. Continual revision of grading systems is essential to improve the diagnostic accuracy, as was introduction of brain invasion criteria in grade II meningioma.

Our distribution of histomorphologic spectrum of meningioma is similar to most of the other studies worldwide as stated in discussion. However we had only few cases of atypical meningioma as compared to others. Genetic profiling and Immunohistochemistry in prospective study may provide more details and elaborate the facts.

\section{Author contribution}

- Dr. Shalaka Khade contributed to study designing, literature search and review, data acquisition and analysis, statistical analysis, manuscript preparation and editing.

- Dr. Ramesh Waghmare contributed to study designing, literature review, data analysis, manuscript preparation and editing.

- Dr. Asha Shenoy contributed to study designing, literature review, data analysis, manuscript preparation and editing. Consensus of all authors was reached in finalization of draft for publication.

Table-1: Histological subtypes of Meningioma cases

\begin{tabular}{|c|c|c|c|c|}
\hline Histological subtype & Male & Female & Total & Percentage \\
\hline Meningothelial & 3 & 7 & 10 & $34.48 \%$ \\
\hline Fibrous & 0 & 1 & 1 & $3.44 \%$ \\
\hline Transitional & 3 & 5 & 5 & $27.58 \%$ \\
\hline Psammomatous & 1 & 4 & 3 & $17.24 \%$ \\
\hline Angiomatous & 2 & 1 & 1 & $10.34 \%$ \\
\hline Secretory & 0 & 1 & 1 & $3.44 \%$ \\
\hline Atypical & 0 & 1 & $\mathbf{2 9}$ & $3.44 \%$ \\
\hline Total & $\mathbf{9}$ & $\mathbf{2 0}$ & $\mathbf{1 0 0} \%$ \\
\hline
\end{tabular}

Table-2: WHO Grading of Meningioma.

\begin{tabular}{|c|c|c|}
\hline WHO Grade & No of cases & Percentage \\
\hline I & 28 & 96.55 \\
\hline II & 1 & 3.44 \\
\hline III & 0 & 0 \\
\hline
\end{tabular}


Table-3: Age and Gender distribution in Meningioma cases

\section{Original Research Article}

\begin{tabular}{|c|c|c|c|c|}
\hline Age & Male & Female & Total & Percentage \\
\hline $0-10$ & 0 & 0 & 0 & $0 \%$ \\
\hline $11-20$ & 1 & 1 & 2 & $6.89 \%$ \\
\hline $21-30$ & 2 & 3 & 5 & $17.24 \%$ \\
\hline $31-40$ & 2 & 5 & 7 & $24.13 \%$ \\
\hline $41-50$ & 1 & 3 & 4 & $13.79 \%$ \\
\hline $51-60$ & 2 & 5 & 7 & $24.13 \%$ \\
\hline $61-70$ & 1 & 3 & 4 & $13.79 \%$ \\
\hline & 9 & 20 & 29 & $100 \%$ \\
\hline
\end{tabular}

Table-4: Comparison of incidence of histological subtypes in various studies.

\begin{tabular}{|c|c|c|c|c|c|}
\hline \multirow{2}{*}{ Study } & \multicolumn{5}{|c|}{ Histological subtypes } \\
\cline { 2 - 6 } & Meningothelial & Fibrous & Transitional & Psammomatous & Angiomatous \\
\hline $\begin{array}{c}\text { Patil \& Sondankar, } \\
2016(\mathrm{n}=87)\end{array}$ & $43.68 \%$ & $5.75 \%$ & $24.13 \%$ & $10.34 \%$ & $0 \%$ \\
\hline $\begin{array}{c}\text { Shri Lakshmi, 2015 } \\
(\mathrm{n}=128)\end{array}$ & $23.44 \%$ & $23.44 \%$ & $15.63 \%$ & $21.88 \%$ & $2.34 \%$ \\
\hline $\begin{array}{c}\text { Gadgil et al, 2016 } \\
(\mathrm{n}=313)\end{array}$ & $22.7 \%$ & $22 \%$ & $24.2 \%$ & $12.7 \%$ & $1.27 \%$ \\
\hline $\begin{array}{c}\text { Shah et al, 2013 (n=51) } \\
\text { Present study (n=29) }\end{array}$ & $37 \%$ & $16 \%$ & $10 \%$ & $19 \%$ & $0 \%$ \\
\hline
\end{tabular}

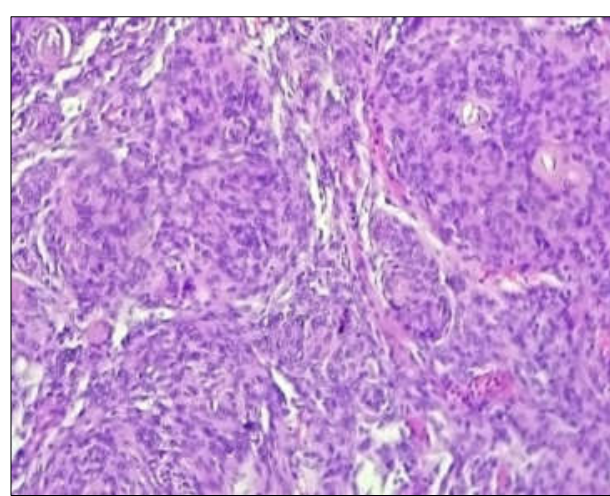

Figure-1: Photomicrograph showing meningothelial cells arranged in lobules (H \& E X100)

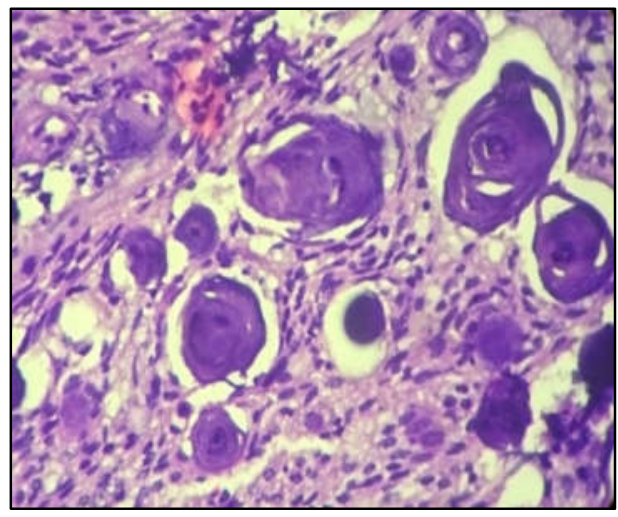

Figure-3: Psammomatous meningioma showing numerous of psammoma bodies (H \& E X400)

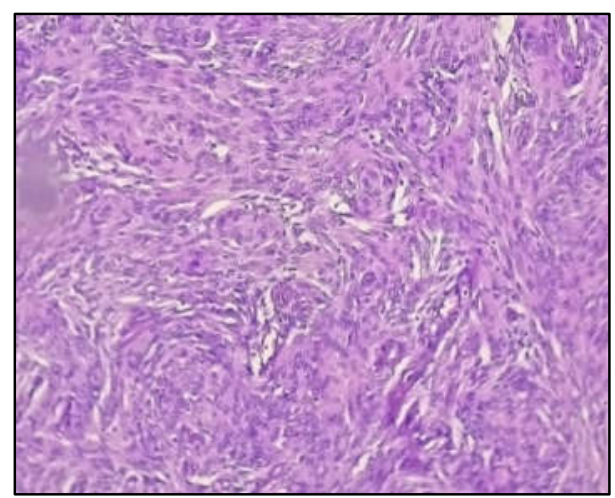

Figure-2: Transitional meningioma with cells in vague fascicular and lobular arrangement (H \& E X100)

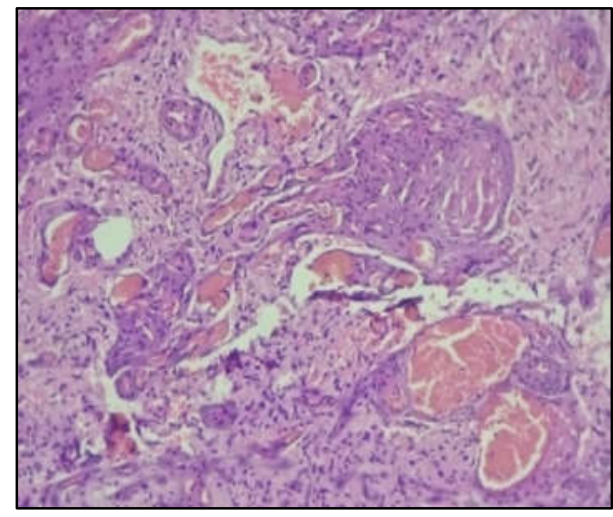

Figure-4: Angiomatous meningioma showing many vascular channels (H \& E X100) 


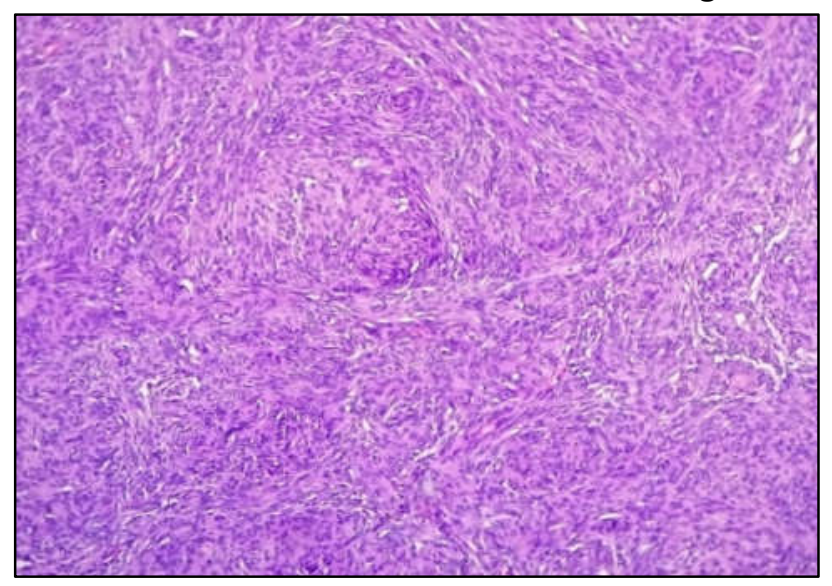

Figure-5: Fibrous meningioma with cells arranged in fascicles and bundles ( $\mathrm{H} \& \mathrm{E}$ X100)

Findings: Nil; Conflict of Interest: None initiated Permission from IRB: Yes

\section{References}

1. Marosi C, Hassler M, Roessler K, Reni M, Sant M, Mazza E, et al. Meningioma. Vol. 67, Critical Reviews in Oncology/Hematology. 2008. p. 153-71.

2. Louis DN, Ohgaki H, Wiestler OD, Cavenee WK. WHO Classification of Tumours of the Central Nervous System. IARC: Lyon. IARC: Lyon 2007. 2007. 164-172 p.

3. Modha A, Gutin PH. Diagnosis and treatment of atypical and anaplastic meningiomas: A review. Vol. 57, Neurosurgery. 2005. p. 538-49.

4. Backer-Grøndahl T, Moen BH, Torp SH. The histopathological spectrum of human meningiomas. Int J Clin Exp Pathol. 2012;5(3):231-42.

5. Prayson RA. Pathology of Meningiomas. In: Meningiomas [Internet]. London: Springer London; 2009 [cited 2016 Dec 23]. p. 31-43. Available from: http:// link. springer. com/10. 1007/978- 1-84628- 7848 _5

6. Basu K, Majumdar K, Chatterjee U, Ganguli M, ChatterjeeS. En plaque meningioma with angioinvasion. Indian J Pathol Microbiol [Internet]. 2010;53(2):31921. Available from: http://www.ncbi. nlm.nih.gov/ entrez/query.fcgi? $\mathrm{cmd}=$ Retrieve $\& \mathrm{db}=$ PubMed\&dopt $=\mathrm{C}$ itation \& list_uids=20551544.

7.Paik SS, Jang SJ, Park YW, Hong EK, Park MH, Lee JD. Microcystic meningioma - A case report. Vol. 11, Journal of Korean Medical Science. 1996. p. 540-3.
8. Mahmood A, Caccamo D V, Tomecek FJ, Malik GM. Atypical and malignant meningiomas: a clinicpathological review. Neurosurgery [Internet]. 1993; 33 (6):955-63. Available from:http://meta. wkhealth.com /pt/pt-core/template-journal/lwwgateway/media/landing page. $\mathrm{htm}$ ?issn $=0148-396 \mathrm{X} \&$ volume $=33 \&$ issue $=6 \&$ spage $=955$

9. Louis DN, Perry A, Reifenberger G, von Deimling A, Figarella-Branger D, Cavenee WK, et al. The 2016 World Health Organization Classification of Tumors of the Central Nervous System: a summary. Vol. 131, Acta Neuropathologica. 2016. p. 803-20.

10.Shah S, Gonsai RN, Makwana R. HISTOPATHOLOGICAL STUDY OF MENINGIOMA IN CIVIL HOSPITAL, AHMEDABAD. Int J Curr Res Rev. 2013;5(3):76-82.

11. Gadgil NM, Margam SR, Chaudhari CS, Kumavat PV. The histopathological spectrum of meningeal neoplasms. Indian J Pathol Oncol [Internet]. 2016;3 (3): 432-6. Available from: http://www.indianjournals. com/ijor.aspx ?target $=$ ijor:ijpo \&volume $=3 \&$ issue $=3 \&$ art icle $=014$

12.Reddy R, Singh R. Histopathological spectrum of meningioma and its variants. Asian Pacific J Heal Sci. 2016;3 (1):151-5.

13. Lakshmi SS. Meningiomas: A Clinicopathological study. Int J Med Res Heal Sci [Internet]. 2015;4(4): 827-31. Available from: http://www. indianjournals. com/ijor.aspx?target $=$ ijor:ijmrhs $\&$ volume $=4 \&$ issue $=4 \&$ article $=021$ 
14.Ruiz J, Martínez A, Hernández S, Zimman H, Ferrer M, Fernández $\mathrm{C}$, et al. Clinicopathological variables, immunophenotype, chromosome 1p36 loss and tumour recurrence of 247 meningiomas grade I and II. Histol Histopathol. 2010; 25(3):341-9.

15.Desai P, Patel D. Histopathological study of meningioma. Int $\mathrm{J}$ Med Sci Public Heal [Internet]. 2016;5 (2): 327-30. Available from: http://www. scopemed. org $/$ ?mno $=206109$

16. Bansal D, Diwaker P, Gogoi P, Nazir W, Tandon A. Intraparenchymal angiomatous meningioma: A diagnostic dilemma. J Clin Diagnostic Res. 2015; 9 (10) : ED07-ED08.

17. Wang DJ, Xie Q, Gong Y, Wang Y, Cheng HX, Mao Y, et al. Secretory meningiomas: Clinical, radiological and pathological findings in 70 consecutive cases at one institution. Int J Clin Exp Pathol. 2013; 6 (3): $358-74$.

\section{Original Research Article}

18. Regelsberger J, Hagel C, Emami P, Ries T, Heese $\mathrm{O}$, Westphal M. Secretory meningiomas: a benign subgroup causing life-threatening complications. Neuro Oncol. 2009;11:819-24.

19. Louis DN, Ohgaki H, Wiestler OD, Cavenee WK, Burger PC, Jouvet A, et al. The 2007 WHO classification of tumours of the central nervous system. Vol. 114, Acta Neuropathologica. 2007. p. 97109.

20. Riemenschneider MJ, Perry A, Reifenberger G. Histological classification and molecular genetics of meningiomas. Lancet Neurol. 2006; 5 (12): $1045-54$.

21.Taghipour M, Rakei SM, Monabati A. The role of estrogen and progesterone receptors in grading of the malignancy of meningioma. Iran Red Crescent Med J. 2007; 9 (1):17-21.

\section{How to cite this article?}

Khade S, Waghmare R, Shenoy A. Histopathological study of meningioma in a tertiary care centre: a two years experience. Trop J Path Micro 2019;5(1):1-7.doi:10.17511/jopm.2019.i01.01. 